\title{
VIRTUAL ENVIRONMENTS TO COMMUNICATE BUILT CULTURAL HERITAGE: A HBIM BASED VIRTUAL TOUR
}

\author{
R. Argiolas ${ }^{1 *}$, V. Bagnolo ${ }^{1}$, S. Cera ${ }^{1}$, S. Cuccu ${ }^{1}$ \\ ${ }^{1}$ DICAAR, University of Cagliari, Cagliari, Italy - (raffaele.argiolas, vbagnolo, sara.cuccu)@ unica.it, cera.simone@gmail.com
}

Commission V, WG V/7

KEY WORDS: HBIM, Virtual Tour, Digital Environment, Cultural Heritage, Complex of Santa Croce, Cagliari.

\begin{abstract}
:
HBIM methodology is nowadays widely used for the management of all aspects of architectural heritage, from survey to analysis, up to protection and management issues. This interest is due to the potential that HBIM methodology offers in terms of collection, processing, management and sharing of information, through a multidimensional and multidisciplinary approach. Practical application of HBIM are the Scan-to-BIM processes, i.e. the digital reproduction of architectures starting from survey methodologies based on laser scanning and photogrammetry.

An increasingly frequent application of HBIM models is their integration in game engines for educational or communicative purposes. Actually, examples of AR and VR applications, serious games or virtual tours employing such models are increasingly frequent. Indeed, such tools allow the generation of virtual immersive environments in which the user is free to navigate or interact with objects. The use of virtual environments that reproduce real places or architectures, is able to generate new attraction and interest in users, while facilitating immaterial accessibility and, allowing a dynamic formulation of content, greater ease of understanding and reading calibrated to the user. The paper aims at the development of a virtual tour set entirely in the former Jesuitical Complex of Santa Croce, located in the historical district of Castello in Cagliari. This tour will be a potential tool to support the understanding and communication of historic architecture by going to the virtual accessibility of the complex.
\end{abstract}

\section{INTRODUCTION}

The HBIM methodology is now widely applied in the management of multiple aspects of built heritage, from the processes of knowledge of the survey and analysis, up to the issues related to their protection and management. The growing interest in HBIM is due to the potential that it can offer in terms of collecting, processing, managing and sharing information, in a multidimensional and multidisciplinary approach.

A widespread practical application of HBIM workflows are the so-called Scan-to-BIM processes, i.e. the digital reproduction of built architectures starting from survey methodologies based on laser scanning and digital photogrammetry technologies.

The BIM environment proves to be extremely effective and promising in the communication of the built environment. Today we can find an increasingly frequent application of HBIM models integrated into game engines for educational or dissemination purposes. So, there are more and more examples of AR and VR applications, serious games or virtual tours using BIM. (Osello et al., 2018). With these tools we can generate virtual immersive environments that allow the user to navigate in 3D space and / or interact with objects.

The use of virtual environments that reproduce real places and architectures is able to generate new attraction and interest in users. This also facilitates intangible accessibility and allows for a dynamic formulation of contents and greater cognitive accessibility, facilitating an understanding and a reading calibrated on the various possible users.

Virtual environments can be further enriched with information derived from the same model, or integrated from the history of the architectures represented, from indirect sources, or even on the relevant urban and social contexts, with significant advantages both in the didactic and communication approach.
In addition, the use of software designed outside the purely AEC environments, such as game engines, allows a high degree of customization of the finished product; this allows the development of tools that can be adapted to occasional users or those without the necessary skills to use specialized software, such as those dedicated to the visualization of BIM models.

The research aims at the development of a virtual tour set entirely in the former Jesuitical Complex of Santa Croce, located in the historical district of Castello in Cagliari. This tour will be a potential tool to support the understanding and communication of historic architecture by going to the virtual accessibility of the complex. A theme, the latter, of extreme relevance in the historical period we are living, during which the sectors of culture and education have been among the most affected by the Covid-19 crisis. In this first phase of the research, the work began by applying the methodology to a limited portion of the Complex of Santa Croce, the atrium designed by Felice De Vincenti in the 18th century. (Fig. 1), with the aim of extending the process to the entire monument.

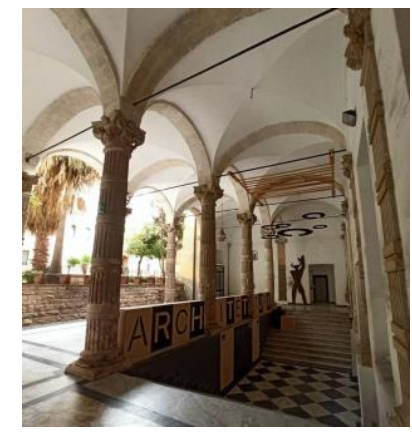

Figure 1. The atrium of the Complex of Santa Croce in Cagliari (Italy) 


\section{METHODOLOGY}

\subsection{HBIM and heritage studies}

Although it was born as a methodology designed for new construction, the BIM methodology is based on a series of foundations that have led to an increasing interest in the field of the study of the built heritage. The multi and interdisciplinary approach, the extension of the vision beyond the three classic spatial dimensions, going to implement time, costs, sustainability and management, as well as a conception of the building not only as an object in itself but as a union of elements that represent and contain information and relationships, are key factors of BIM and also essential when working on the built heritage. The transition from as-designed to as-built, however, has required a paradigm shift, the development of a new approach aimed at reading and understanding the heritage first, and then its representation and communication. According to this logic was born what Murphy (2009) called HBIM. Although over time the definition of HBIM has undergone some changes, the essence has remained essentially unchanged: collect survey information, extract from them through a process of reverse engineering data inherent in the characteristics of the building and create a digital copy. This methodology finds fulfilment in Scan-to-BIM processes (Fig. 2 ), in which the complexities of architectural elements are detected using modern digital technologies, such as laser scanning or photogrammetry, and processed in order to obtain parametric objects that can contain data relating to real objects, regardless of whether they are geometric, physical, historical data and so on (López et al., 2018).

The models thus obtained allow a wide range of uses, ranging from static to energy analyses, from the formal study of the building to the functional one, but also, as in the case presented, to the communication of architecture through digital tools.

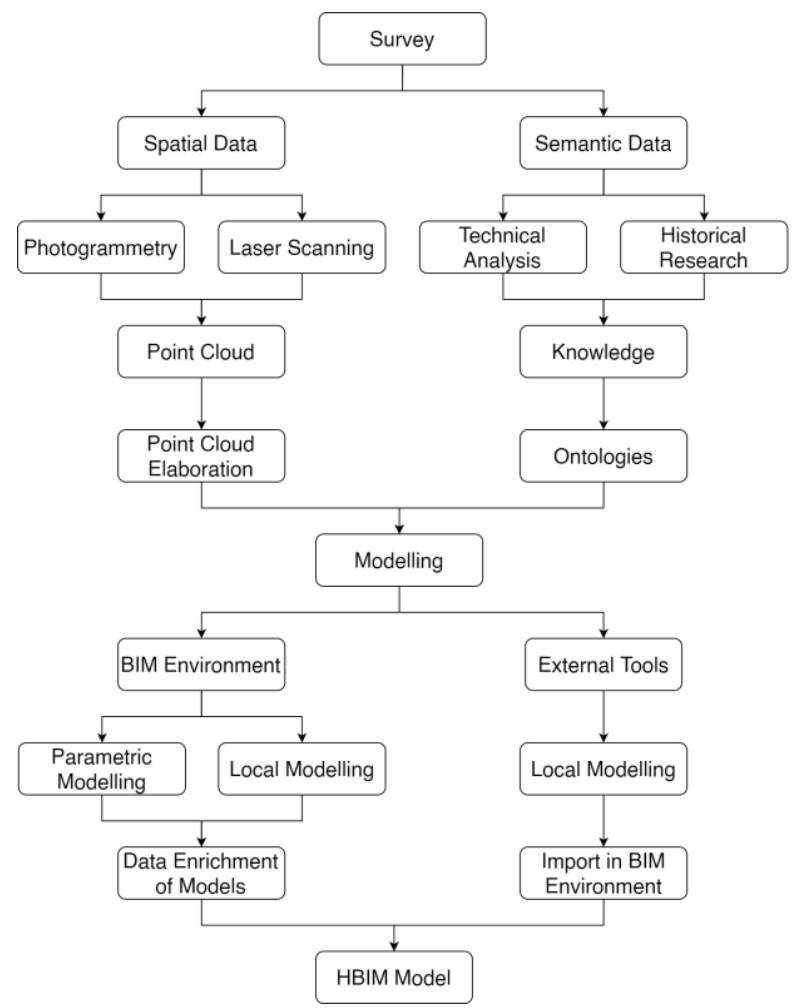

Figure 2. Standard workflow in Scan-to-BIM processes.

\subsection{Virtual environments for heritage communication}

What characterises the experience of a virtual environment is the involvement with the space, being able to walk through it and to interact with it, and thus the possibility of creating one's own individual experience within it. The relationship between the person and the virtual environment is a topical subject in several disciplines, and one that deals with it most is game studies, which draws from various fields, including neuroscience. Before considering the different positions regarding the person-environment relationship, it is appropriate to define what is meant by virtual environment, adopting Calleja's (2009) definition: "virtual environments are computer generated domains which create a perception of traversable space and afford the exertion of player agency. They are populated by objects and often human or AI controlled entities with whom players can interact with.”(Calleja, 2009, p. 2).

The author mainly refers to digital games, but it is particularly important because it allows to separate digital games and virtual reality applications, or more generally cross media technologies, from other virtual spaces such as chats, web pages, or social networks.

The relationship between the user and the virtual world has been debated for a long time and the different approaches are linked by the analysis of the perception of bodily presence in a virtual space (Dourish, 2001; Klevjer, 2006; Minsky, 1980; Taylor, 2002). The issue obviously remains open and constantly evolving, but by referring as anticipated to game studies, we examine two positions: Murray's (1997) concept of immersion and Calleja's (2011) concept of incorporation. Murray defines the concept of immersion, referring to video games, as an alternative dimension outside of reality, in which one remains almost suspended as long as "the active creation of belief" (Murray, 1997, p. 107) persists, i.e. the will to actively and creatively participate in immersion.

Murray's concept has been overtaken by that of incorporation: "[...] the absorption of a virtual environment into consciousness, yielding a sense of habitation [...]" (Calleja, 2011, p. 169). Calleja no longer distinguishes between the traditional meanings of the term, as assimilation into the mind and embodiment, but merges them; the notion can be understood as a reinforcement of introjected involvement, a synthesis of movement into an inhabitable space, which can also involve other dimensions such as narrative and social.

Taking advantage of the factors just described and evolving technologies, virtual environments are increasingly being used for education, training, and communication across an everwidening range of industries. In fact, there are countless examples in which this type of tool is used by calibrating its characteristics according to the type and age of the user to whom they refer, but also to the level and type of education (Damala et al., 2016; Mortara \& Catalano, 2018; Okura et al., 2015; Silva et al., 2018); for these reasons, virtual environments often become a fundamental component to promote immaterial accessibility.

The use of virtual environments, understood as computergenerated traversable spaces inhabited by users, is now also part of the cultural heritage sector, where cross-reality technologies such as virtual reality, augmented reality and other forms of mixed-reality, have been experimented for some time (O'dwyer 
et al., 2021). The applications of these technologies, together with the production of virtual tours and serious games, are widely used tools for the promotion and communication of cultural heritage (Arcese et al., 2011; Bekele et al., 2018), and in which where BIM models and game engines are also starting to take centre stage (Bagnolo et al., 2021; Milková et al., 2019).

\subsection{Virtual tour design}

In order for the virtual tour to be effective from the point of view of communicating the studied architecture, it is necessary that the architecture is faithfully reproduced. This allows us to understand not only the architecture from a material point of view, i.e. regarding materials, forms and construction techniques, but also from the point of view of the perception of spaces and the experiences they offer. This does not mean, however, that hyper-modelling aimed at an extreme level of detail is necessary; instead, it is important that the virtual environment present a certain degree of synthesis, based on a critical reading of the architectural elements.

The degree of accuracy in the rendering of models produced by BIM methodology has, over time, been indicated in a variety of ways. The one currently most widely used is certainly the LOD (BIMForum, 2021) (Fig. 3), which is based on a process of progressive enrichment of information, whose maximum level to be reached is established according to the purpose of the model (Brumana et al., 2018).

According to this classification the models used in the contribution have a LOD of 200 for the elements particularly complex whose representation more detailed turns out too much expensive in terms of resources and performances, without that there is a real benefit for the established objectives for the tour; an example of elements with LOD 200 are the capitals, represented by schematic models that are recognizable by function, volume, and location, but not sufficient for detailed measurements. The LOD is of 300 instead for the elements for which, given the relative simplicity of the shapes, a good degree of precision can be obtained without an excessive expenditure of resources.

It is also evident the advantage of being able to take advantage of a univocal link between objects and information to be provided to the user from time to time. This is what is offered to us by the Scan-to-BIM flows for HBIM representation of the built heritage.

In the proposed work, these flows are extended with an additional step, that of the tour development within the game engine. Thus, the workflow can be summarized into two main parts: the Scan-to-BIM for model generation and information gathering, and the tour development. Since the modelling process does not deviate from the well-established standard methodology (Badenko et al., 2019), the contribution introduces in synthetic way the passages that have lead to the creation of the model and focuses instead on the final part of the process, the development of the virtual tour.

It's in this part that the generated models, and enriched with information in the BIM environment, are imported within the game engine for the design and implementation as virtual environment of the prototype (Fig. 4).

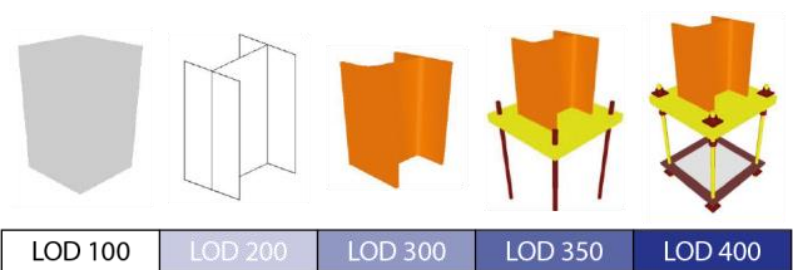

Figure 3. Example representation of information in BIM according LOD Specification., Source: BIMForum (2021).

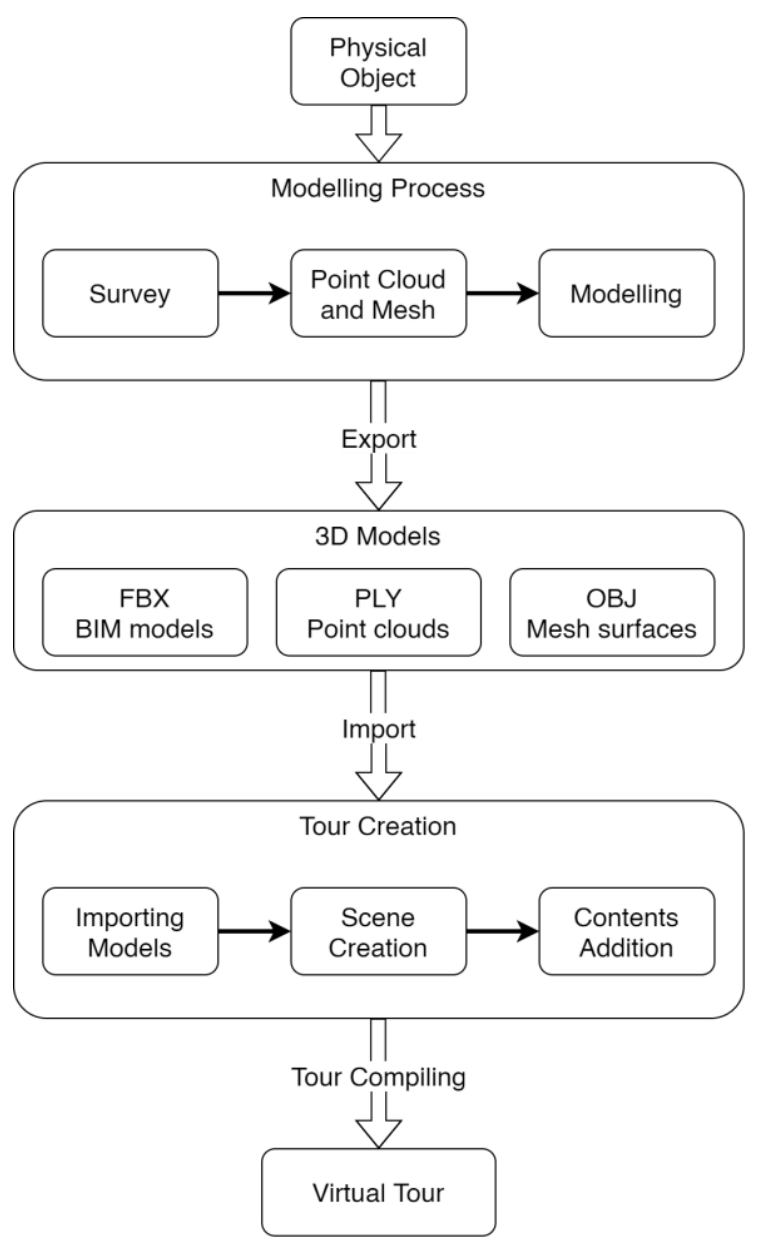

Figure 4. Workflow leading from the survey to the tour compiling.

\section{CASE STUDY}

The chosen case study is located in Castello, the main of the four historical quarters of the city of Cagliari, founded in the 13th century by the Pisans, after the destruction of the Judicial capital of Santa Igia (Scano, 1934). In the second half of the 16th century, the Jesuit architects Giandomenico da Verdina and Giovanni Maria Bernardoni, students of Father Giovanni Tristani, introduced for the first time the Renaissance aesthetics in Sardinia, through the construction of a college attached to the Jesuit Church of Santa Croce, the first of the organically baroque architectures in Sardinia (Maltese et al., 2012).

The complex is composed of two bodies located behind the church, separated by a portico but connected by an overpass on the carrer de sancta Creus (Maltese et al., 2012), today's via Corte d'Appello. The body to the west, between the churches of Santa Croce and Sacro Monte di Pietà, was completed in 1661, 
while the body to the east was later enlarged by the Piedmontese architect Antonio Felice De Vincenti between 1725 and 1773 (Cabras, 1966; Garofalo, 2012). De Vincenti created a two-level atrium open on one side to a cloister-garden (Salinas \& Freddi, 1958). The large space is architecturally defined by ten cross vaults arranged in a double row resting on elegant fluted columns (Fig. 5).

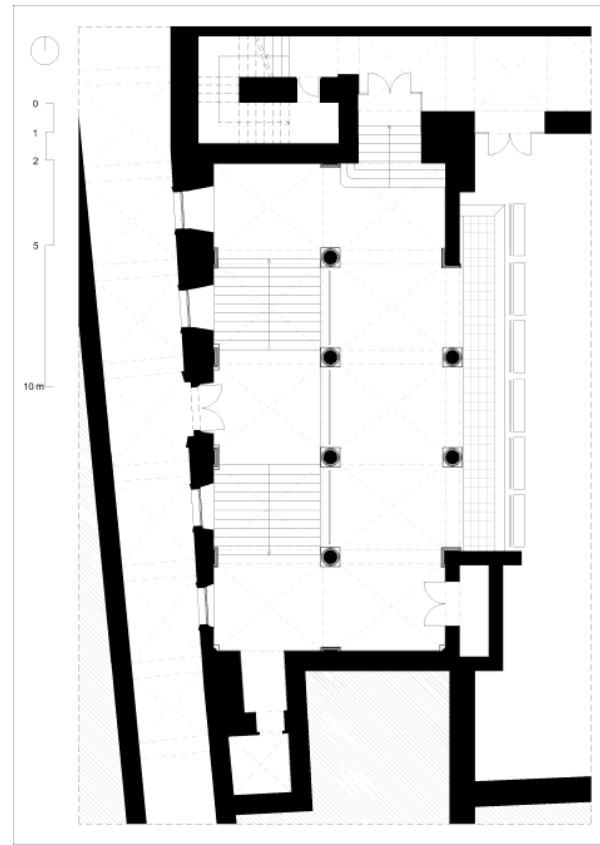

Figure 5. The plan of the atrium of the Complex of Santa Croce in Cagliari.

Officially handed over to the State in 1773, following the abolition of the Jesuit order, the complex housed various functions in successive periods.

The complex is currently one of the seats of the Faculty of Engineering and Architecture of the University of Cagliari.

Specifically, the geometry of each of the ten crosses of the atrium created by De Vincenti is generated by the intersection of two different barrel vaults: one deriving from the extrusion of a round arch and one deriving from the extrusion of a threecentered arch; this therefore makes the crosses composed of panels equal to two by two. The framework of the four perimeter arches rests on columns with a regular interaxis of 3.00 meters on the north-south axis and 3.70 meters on the eastwest axis.

The columns are composed by an attic base on which rests a fluted shaft crowned by a capital decorated with volutes and drapes of flowers and fruit.

In this case, the shaft is composed of five drums defined by 20 vertical grooves with listel edges, marked between them by four horizontal bands moulded according to the motif listel - groove - listel. The shaft has an entasis at about one third of its height. The stylistic motifs of the 6 columns are reproduced in the same way, this time on a rectangular base, in the four corner pilasters - two arranged on a concave angle and two on a convex angle and on the six pilasters next to the perimeter walls.

\section{DEVELOPMENT OF THE VIRTUAL TOUR}

\subsection{The Scan-to-BIM process}

As already mentioned, the work begins by applying to the atrium of the complex a classic Scan-to-BIM process, i.e. starting with the design and execution of a survey using laser scanning technology. The survey was conducted with a Leica HDS 7000 laser scanner and consisted of 9 scanning stations for a total of 269.24M points (Fig. 6).

The scans were subsequently recorded and cleaned up on Autodesk ReCap, in order to obtain a point cloud directly importable in Revit for modelling.

The modelling was conducted in three ways: elements belonging to native Revit categories, such as stairs, walls, floors, etc. were modelled with the predefined tools in the software; more complex elements, but still manageable with Revit parametric modelling tools, such as mouldings, column bases or railings, were modelled by creating specific families. On the other hand, vaults and column shafts, belonging to categories of elements that have already been the subject of research in the past on the use of algorithmic modelling tools applied to complex historical elements, have been generated according to this methodology (Bagnolo \& Argiolas, 2021; Bagnolo et al., 2019). 


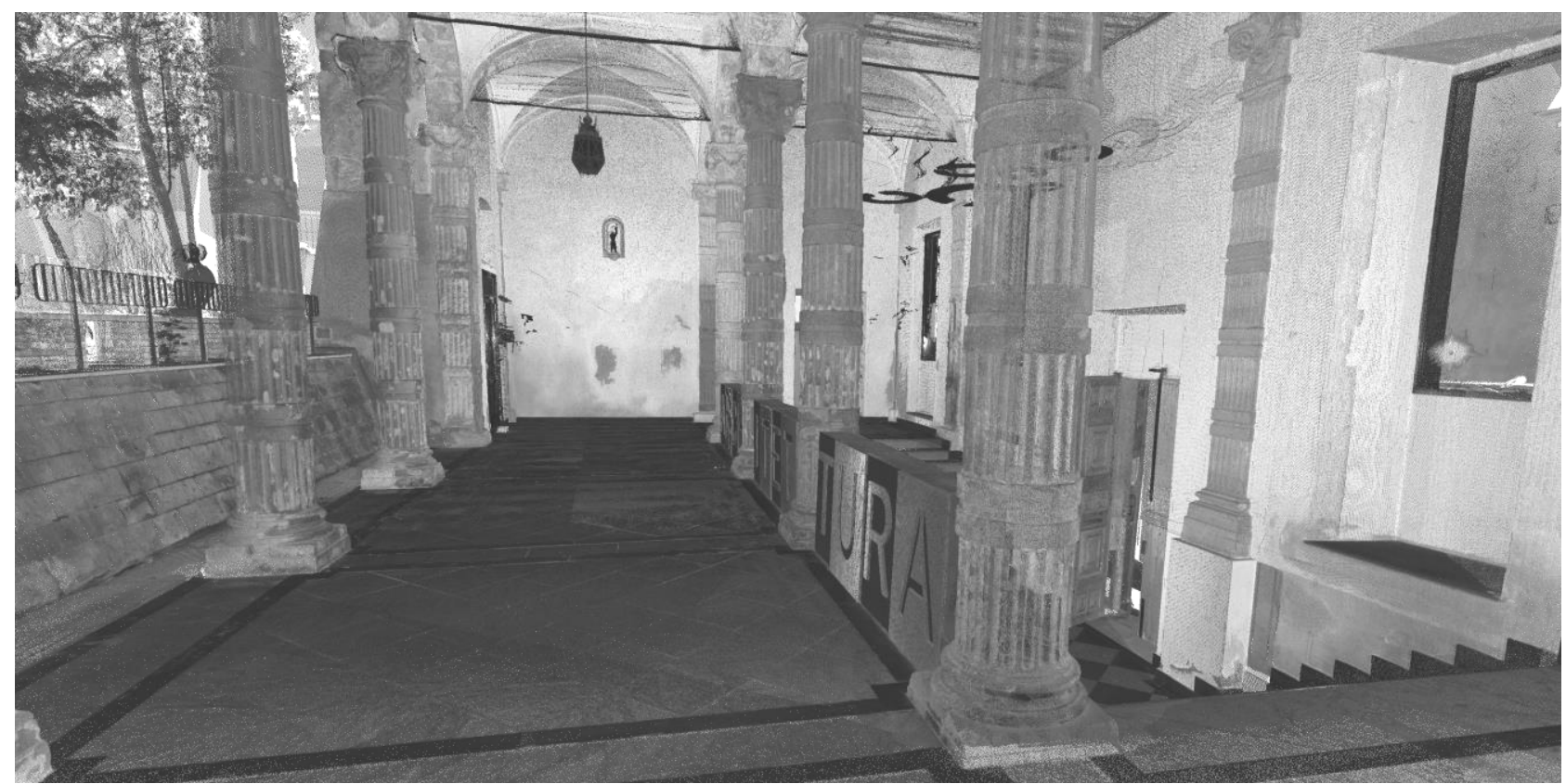

Figure 6. An image of the registered point cloud of the atrium.

The capitals of the columns finally fall into a category that requires a different approach; they, in fact, are geometrically very complex elements, whose parametric modelling is possible but extremely expensive in terms of time and resources. In this particular case it is possible to opt for a synthesis modelling that gives a recognizable representation of the type and function of the object but does not define the individual details; this solution leads to objects with a level of detail LOD 200 which, as already mentioned in previous chapters, is considered functional for the purposes of the tour.

An alternative solution, diametrically opposed to the one just described, is represented by the use of a mesh model directly obtained from the point cloud; this would lead to a model certainly richer in details and corresponding to the real object, but the richness of details would be beyond the scope of the purposes set against a greater demand for resources in the generation, management and use of the final model. The final BIM model is shown in Fig. 7.

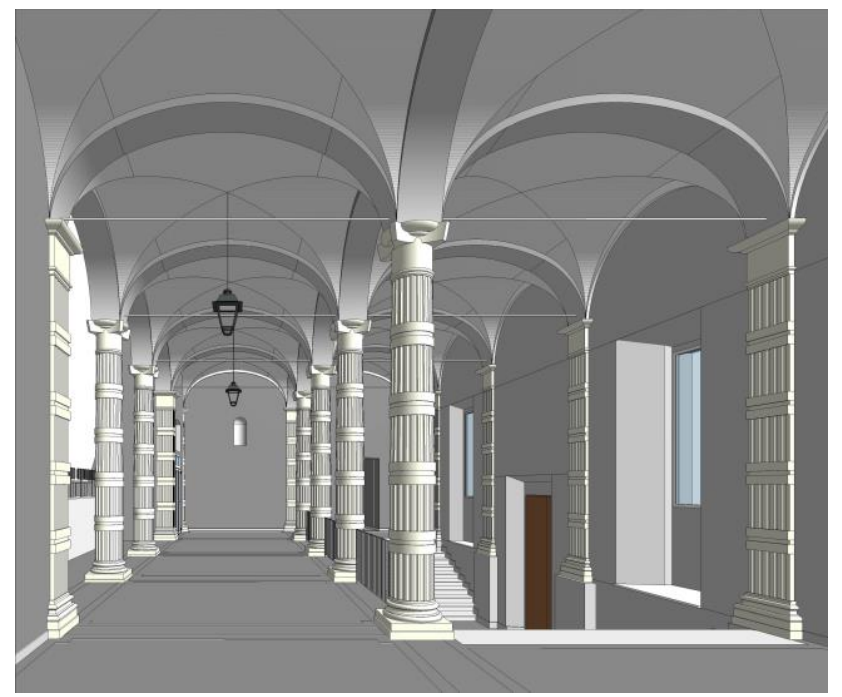

\subsection{From Revit to Unity}

Nowadays there are multiple software solutions of game engines (Smith et al., 2019) but, for operational continuity with other ongoing research, the choice fell on Unity. The initial choice to use unity was dictated by the relative simplicity with which it is possible to develop small prototypes, also thanks to the wide choice of free assets; Unity's direct competitor, the Unreal Engine, is superior in many ways but none of them really useful for the purpose and level of development set (Christopoulou \& Xinogalos, 2017).

Regarding the interchange of data between software involved, among the various file formats exportable from Revit, BIM environment chosen for the research, and usable in Unity natively, it was decided to use the FBX format; the main reasons for this choice are the direct export and import of this format between the applications involved and the possibility of preserving not only the materials but also the hierarchies of the elements, as they are set in Revit (Lee et al., 2019).

As far as materials are concerned, although Revit does not natively allow the export of materials within FBX models, this can be achieved through the software API; there are several plugins and scripts that allow the export of materials and textures embedded in the FBX model.

The model becomes an environment explorable by the user thanks to the integration of a basic movement system; moreover, thanks to the preconfigured collision management in Unity, the user is given the freedom to perform further actions beyond the normal walking, such as climbing or descending steps, jumping or even "falling" from elevated parts, useful to promote immersivity in the environment. Exploration is also encouraged, and in a certain sense rewarded, through the discovery of additional information by interacting with the architectural elements or furnishings present in the scene.

Figure 7. BIM model of the atrium. 
These are just a few of the first hypotheses of interactions that can be offered to the user; however, the use of a game engine to visualize BIM models offers many other ideas. Through the development of simple scripts, it is possible to manage, for example, the exchange of models in real time in order to show how environments have changed over time, or to change lighting conditions to simulate the passage of time.

\subsection{Features in the virtual tour}

Through the implementation in the game engine, it was possible to build the different parts that make up the experience of the virtual tour. The design of the tour is totally based on the possibility to explore the architectural model and on the interaction with the elements that compose it in order to understand and transmit the knowledge of the same architecture. The tour starts with a guide screen, recallable at any time through the ESC key that has the task of illustrating through a simple and intuitive text tutorial all the tour commands (Fig.8).

The commands are those found in any FPS video game (first person shooter). Through the WASD keys you can walk or run within the space; the movement of the mouse allows you to rotate the user's view in all directions, while through the left mouse button you can start an interaction.

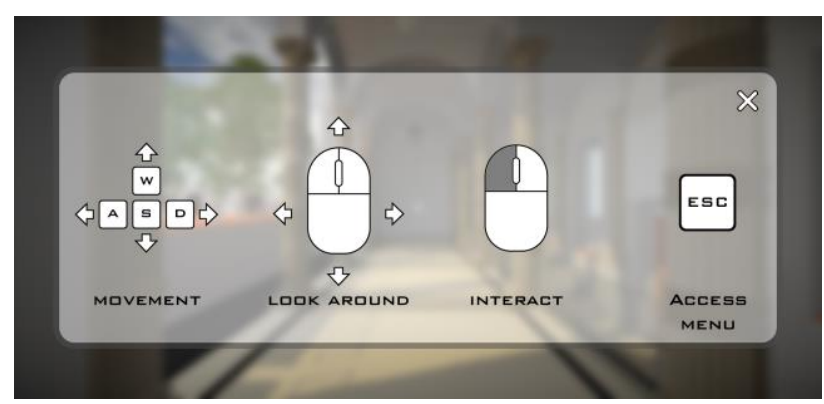

Figure 8. The tutorial screen with the controls on the tour.
The possibility of interaction with an object is shown to the user through the change in size of the crosshair. Through the interactions it is possible to interrogate different architectural objects that make up the scene, allowing to obtain further information and keys to the space that the user is navigating, expanding the knowledge and understanding of the work.

The elements for which interactions have been configured are currently three: the opening of information panels, the superimposition of technical images on the model and the visualization of panoramic images of certain areas.

For example, clicking on the columns it is possible to make appear an informative panel containing various information on materials, styles, mouldings and geometric constructions, or still referable to the reliefs effected compared to the classical treatise. This favours the transmission of the knowledge of the work in object and supplies the necessary instruments for the understanding of the relative treatise (Fig. 9).

Interacting with the pilasters, on the other hand, it is possible to make a layer appear which, superimposed on the object, describes the material discontinuities detected in the analysis of degradation previously carried out. Through this tool it is possible to communicate information about natural and anthropic degradation of architectural elements, highlighting any damage caused by incorrect maintenance practices or previous restoration works (Fig. 10).

The third type of interaction foreseen allows, by clicking on one of the "bubbles" present in the scene, to modify the navigation environment passing from the $3 \mathrm{D}$ model to the visualization of the space through the spherical photos; to guarantee a greater cleanliness of the model, the interacting "bubbles" appear only when the user is below a certain distance from them (Fig. 11).

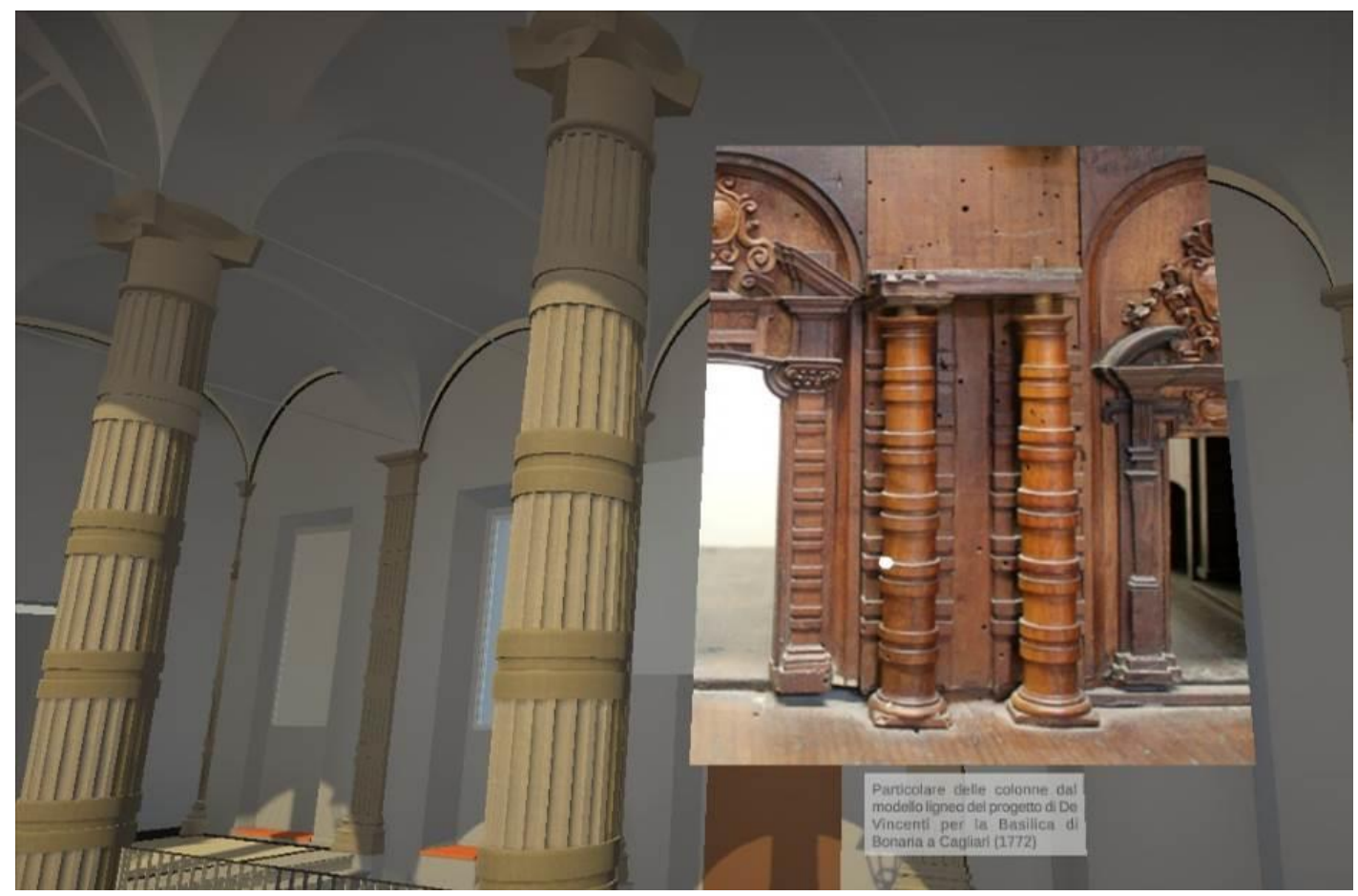

Figure 9. An example of informative panel in the tour showing a detail of the banded columns adopted by De Vincenti in the wooden model for the new church of Nostra Signora di Bonaria. 

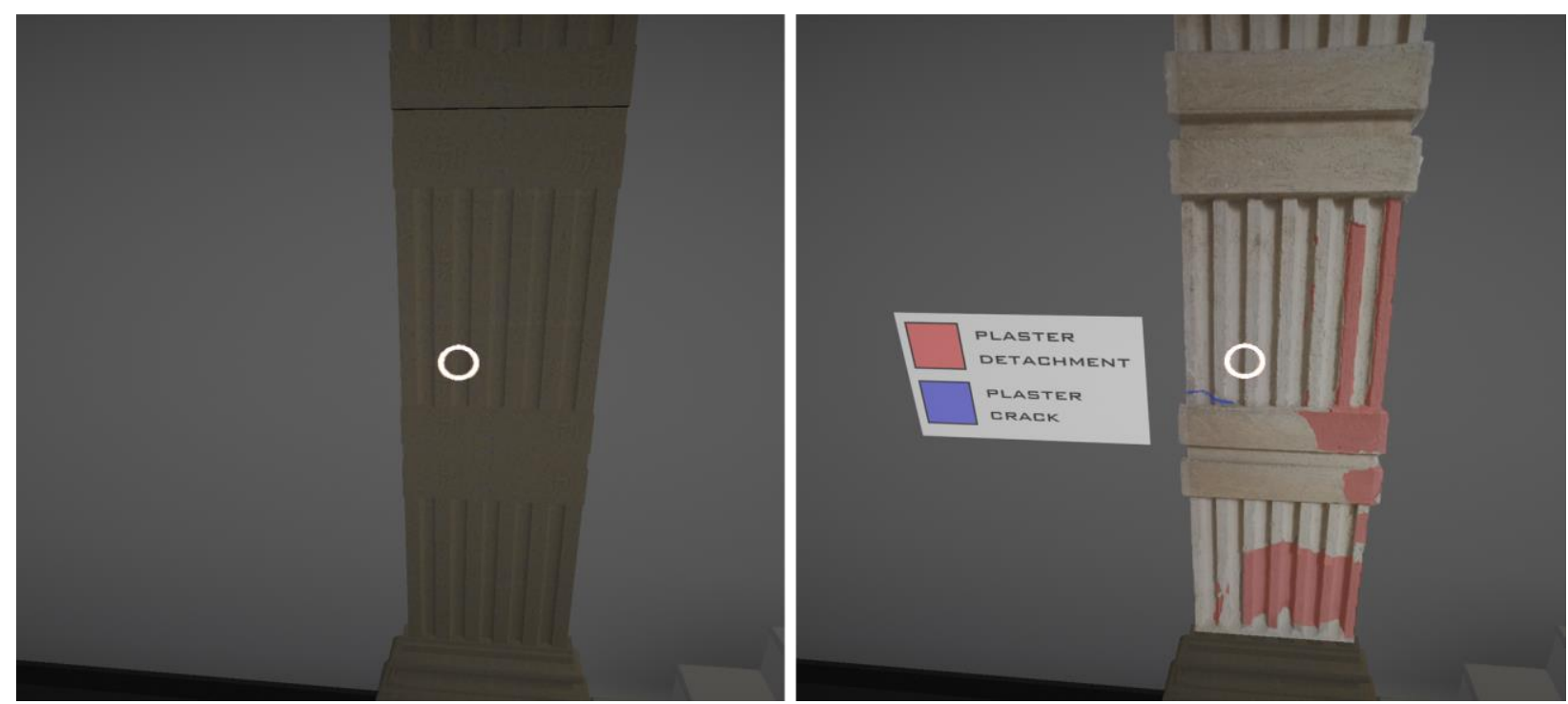

Figure 10. An example of an interaction providing information about a simple decay state analysis. On the left the model before the interaction, on the right the decay analysis overlaid on the model after the interaction.
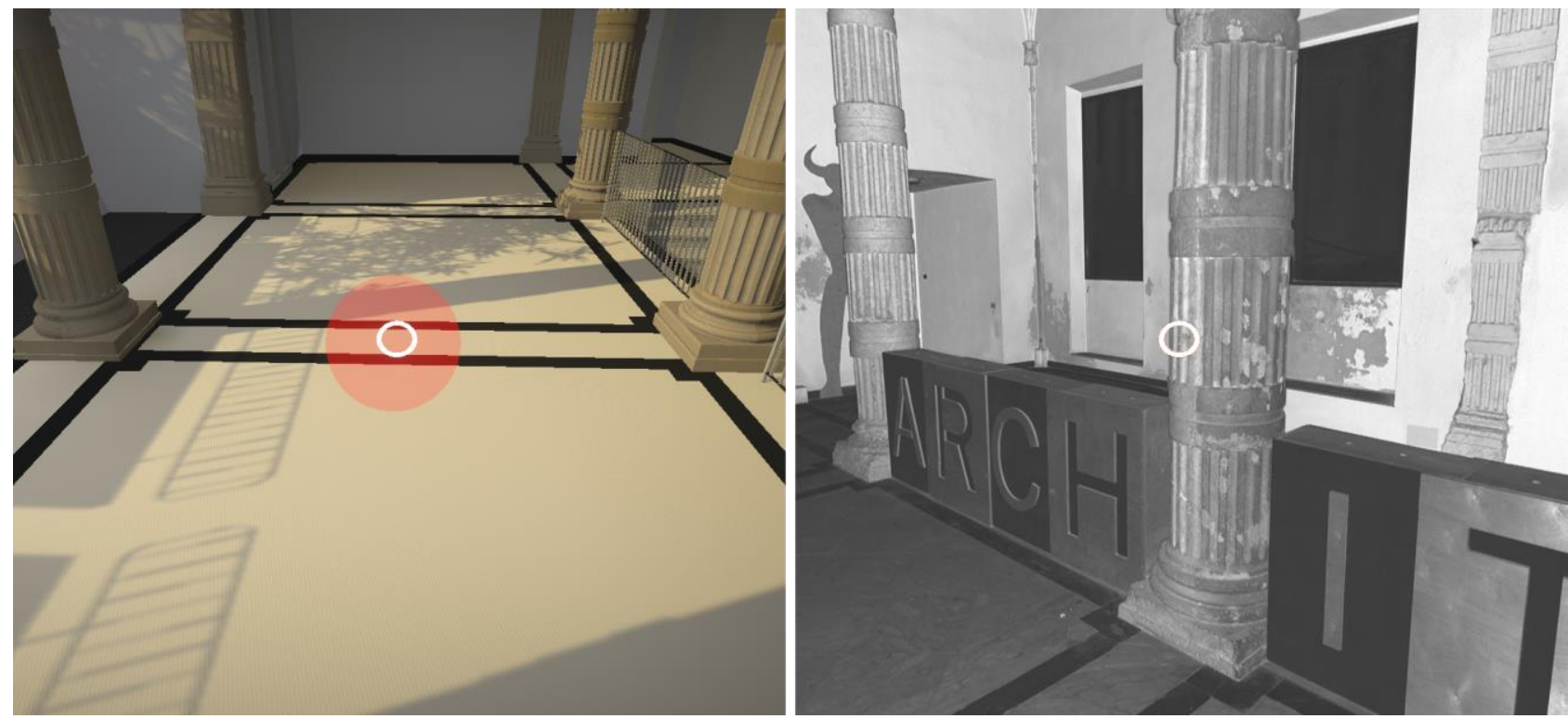

Figure 11. Interactive "bubble" (left) and panoramic photo visualization of the current state of the atrium (right).

\section{CONCLUSIONS}

The aim of this paper is to design a prototype of virtual tour for the communication of the cultural heritage; in particular, taking advantage of the potentialities of the HBIM methodology together with the flexibility of the game engines, a virtual tour set in the Complex of Santa Croce in Cagliari has been developed.

Already from the first phases of the work, the advantages of being able to have informative models directly transposable in the development software, preserving the geometric characteristics and part of the data such as materials or lights, are evident. Moreover, the game engine has allowed the extension of the information available to the user through interactions with the objects present in the tour.
In the future, the work aims to expand the explorable spaces, currently limited to the atrium of the complex, and hypothesize alternative ways of experiencing the virtual environments represented, such as the implementation of game mechanics.

\section{ACKNOWLEDGEMENTS}

Research project funded by Fondazione di Sardegna - year 2019. Surveying, modelling, monitoring and rehabilitation of masonry vaults and domes (RMMR). CUP: F72F20000320007

\section{AUTHORSHIP CONTRIBUTIONS}

Argiolas R. carried out the laser scanner survey, elaborated the point cloud, developed the prototype of the virtual tour. 
Argiolas R. and Cera S. made the BIM models and all the drawings/images.

Although the study was jointly performed by the authors, most of the paragraph 1 was written by Vincenzo Bagnolo; most of the paragraphs 2.1, 2.3, 4.1 and 4.2 were written by Raffaele Argiolas; most of the paragraphs 3 and 4.3 were written by Simone Cera; most of the paragraph 2.2 was written by Sara Cuccu; the Conclusions were jointly written by all authors.

\section{REFERENCES}

Arcese, G., Di Pietro, L., \& Guglielmetti, R. 2011, 2011/01//. The Augmented Reality in The Cultural Heritage Sector.

Badenko, V., Fedotov, A., Zotov, D., Lytkin, S., Volgin, D., Garg, R. D., \& Liu, M. 2019. Scan-to-Bim methodology adapted for different application. ISPRS - Int. Arch. Photogramm. Remote Sens. Spat. Inf. Sci., XLII-5/W2, 1-7. https://doi.org/10.5194/isprs-archives-xlii-5-w2-1-2019

Bagnolo, V., \& Argiolas, R. 2021. Scan-to-BIM Process Versus 3D Procedural Modelling of Gothic Masonry Vaults. In From Building Information Modelling to Mixed Reality 17-31. Springer.

Bagnolo, V., Argiolas, R., \& Cuccu, A. 2019. Digital survey and algorithmic modeling in HBIM. Towards a library of complex construction elements. ISPRS - International Archives of the Photogrammetry, Remote Sensing and Spatial Information Sciences, XLII-4/W12, 25-31. https://doi.org/10.5194/isprs-archives-xlii-4-w12-25-2019

Bagnolo, V., Argiolas, R., Cuccu, S., \& Paba, N. 2021. Beyond Hbim: Serious Games and Procedural Modelling for Heritage Dissemination. ISPRS-International Archives of the Photogrammetry, Remote Sensing and Spatial Information Sciences, 46, 55-60.

Bekele, M. K., Pierdicca, R., Frontoni, E., Malinverni, E. S., \& Gain, J. 2018. A Survey of Augmented, Virtual, and Mixed Reality for Cultural Heritage. Journal on Computing and Cultural Heritage, 11(2), 7:1-7:36. https://doi.org/10.1145/3145534

BIMForum. 2021. LOD Specification. https://bimforum.org/LOD/

Brumana, R., Della Torre, S., Previtali, M., Barazzetti, L., Cantini, L., Oreni, D., \& Banfi, F. 2018. Generative HBIM modelling to embody complexity (LOD, LOG, LOA, LOI): surveying, preservation, site intervention-the Basilica di Collemaggio (L'Aquila). Appl. geomat., 10(4), 545-567. https://doi.org/10.1007/s12518-018-0233-3

Cabras, M. 1966. Le opere del De Vincenti e dei primi ingegneri militari piemontesi in Sardegna nel periodo 1720 1745. Centro di Studi per la Storia dell'Architettura,

Calleja, G. 2009, 2009. Experiential narrative in game environments. Breaking New Ground: Innovation in Games, Play, Practice and Theory.,

Calleja, G. 2011. In-game: from immersion to incorporation. MIT Press, Cambridge, Mass.

Christopoulou, E., \& Xinogalos, S. 2017. Overview and comparative analysis of game engines for desktop and mobile devices. Int. J. Serious Games, 4(4). https://doi.org/10.17083/ijsg.v4i4.194
Damala, A., Hornecker, E., van der Vaart, M. J., Van Dijk, D., \& Ruthven, I. 2016. The Loupe: Tangible Augmented Reality for Learning to Look at Ancient Greek Art. Mediterranean Archaeology and Archaeometry, 16(5), 73-85. https://doi.org/10.5281/zenodo.204970

Dourish, P. 2001. Where the action is: the foundations of embodied interaction. MIT Press, Cambridge, Mass.

Garofalo, E. 2012. Le architetture della Compagnia di Gesù in Sardegna (XVI-XVIII secolo). La arquitectura jesuítica, 141192

Klevjer, R. 2006. What is the Avatar? Fiction and Embodiment in Avatar-Based Singleplayer Computer Games University of Bergen].

Lee, G.-h., Choi, P.-h., Nam, J.-h., Han, H.-s., Lee, S.-h., \& Kwon, S.-c. 2019. A Study on the Performance Comparison of 3D File Formats on the Web. International journal of advanced smart convergence, 8(1), 65-74.

López, F. J., Lerones, P. M., Llamas, J., Gómez-GarcíaBermejo, J., \& Zalama, E. 2018. A Review of Heritage Building Information Modeling (H-BIM). Multimodal Technologies and Interaction, 2(2), 21. https://www.mdpi.com/2414-4088/2/2/21

Maltese, C., Serra, R., Madonna, M., Trigilia, L., Segni Pulvirenti, F., Sari, A., Saiu Deidda, A., \& Schirru, M. 2012. Avanguardie architettoniche e urbane nella Sardegna della prima epoca moderna. Ricerche di Architettura: Nuove Prospettive per l'architettura nella Sardegna del XXI secolo, 150.

Milková, E., Maněnová, M., Chadimova, L., \& Ntalianis, K. 2019. 3D technology in the cultural heritage and education context. International journal of education and information technologies, 13, 59-64.

Minsky, M. 1980. Telepresence. Omni Magazine.

Mortara, M., \& Catalano, C. 2018. 3D Virtual environments as effective learning contexts for cultural heritage. Italian Journal of Educational Technology, 26(2), 5-21.

Murphy, M., McGovern, E., \& Pavia, S. 2009. Historic building information modelling (HBIM). Structural Survey, 27(4), 311327. https://doi.org/10.1108/02630800910985108

Murray, J. H. 1997. Hamlet on the holodeck: the future of narrative in cyberspace (Updated edition ed.). The MIT Press, Cambridge, Massachusetts.

O'dwyer, N., Zerman, E., Young, G. W., Smolic, A., Dunne, S., \& Shenton, H. 2021. Volumetric Video in Augmented Reality Applications for Museological Narratives: A User Study for the Long Room in the Library of Trinity College Dublin. Journal on Computing and Cultural Heritage, 14(2), 22:21-22:20. https://doi.org/10.1145/3425400

Okura, F., Kanbara, M., \& Yokoya, N. 2015. Mixed-Reality World Exploration Using Image-Based Rendering. Journal on Computing and Cultural Heritage, 8(2), 9:1-9:26. https://doi.org/10.1145/2700428

Osello, A., Lucibello, G., \& Morgagni, F. 2018. HBIM and Virtual Tools: A New Chance to Preserve Architectural Heritage. Buildings, https://doi.org/10.3390/buildings8010012 
Salinas, R., \& Freddi, M. 1958. Il complesso monumentale di S. Croce a Cagliari. Bollettino Tecnico del Circolo Culturale degli Ingegneri e Architetti Sardi(4).

Scano, D. 1934. Forma Karalis. Cagliari: Edizioni La Zattera, 210 .

Silva, H., Resende, R., \& Breternitz, M. 2018, 4-4 May 2018. Mixed reality application to support infrastructure maintenance. 2018 International Young Engineers Forum (YEF-ECE),

Smith, M., Walford, N. S., \& Jimenez-Bescos, C. 2019. Using $3 \mathrm{D}$ modelling and game engine technologies for interactive exploration of cultural heritage: An evaluation of four game engines in relation to roman archaeological heritage. Digital Applications in Archaeology and Cultural Heritage, 14, e00113.

https://doi.org/https://doi.org/10.1016/j.daach.2019.e00113

Taylor, T. L. 2002. Living Digitally: Embodiment in Virtual Worlds. In R. Schroeder (Ed.), The Social Life of Avatars: Presence and Interaction in Shared Virtual Environments Springer-Verlag ed. London. https://citeseerx.ist.psu.edu/viewdoc/download?doi=10.1.1.12.4 $645 \&$ rep=rep $1 \&$ type $=$ pdf 